\title{
Comparative Evaluation of In Vitro Drug Release Methods Employed for Nanoparticle Drug Release Studies
}

\author{
Suresh K. Paswan and T. R. Saini*
}

Industrial Pharmacy Research Lab, Department of Pharmacy, Shri G. S. Institute of Technology and Science, Indore, India.

\begin{abstract}
The aim of the present study was to experimentally compare the attributes, drawbacks, and limitations of the most commonly employed in vitro drug release test methods for nanoparticle systems and to explore the possibility of one method being adopted as a standard for quality control of nanoparticle-based products. Three in vitro drug release test methods, i.e., direct addition, dialysis bag, and low-pressure ultrafiltration, were employed for evaluation of drug release from tamoxifen-loaded poly(lactic-co-glycolic acid) nanoparticles. Relevant operational characteristics of each test method were compared. Drug release data were fitted in different release kinetics models, i.e., zero order, first order, Higuchi, Hixson-Crowell, and Korsmeyer-Peppas. The coefficient of determination $\left(R^{2}\right)$, release rate constant $(k)$, and release exponent $(n)$ values were calculated. The direct addition method showed rapid initial drug release, whereas a slow release rate was observed in the dialysis bag method. Results of the low-pressure ultrafiltration method were consistent with the direct addition method and various operational characteristics were more realistic than the other two methods. Overall, the findings support that low-pressure ultrafiltration can be considered as a standard regulatory test method for in vitro release of nanoparticle-based formulations.
\end{abstract}

KEYWORDS: Nanoparticles, in vitro release methods, low-pressure ultrafiltration, dialysis bag, direct addition method, dissolution

\section{INTRODUCTION}

C urrently polymeric nanoparticle-based drug delivery systems are being consistently explored for treatment of various diseases such as cancer, tuberculosis, diabetes, parkinsonism, Alzheimer's, cardiovascular diseases, multiple sclerosis, and others. (1-13). Many proprietary nanoparticle-based products have already been approved and several are undergoing clinical trials (14-17).

Nanoparticles in pharmaceutical delivery systems are drug-containing particles with a size ranging from 1 to $1000 \mathrm{~nm}$; the average size is $300 \mathrm{~nm}(17,18)$. A validated in vitro drug release test method with good discriminatory ability and reproducibility is required for quality control of nanoparticle formulations in finished form and during formulation development; however, a standard dissolution test method has not yet been established. Therefore, different scientists evaluate their products by their own methods, which has finally led to non-uniformity in the results and interpretations of dissolution studies. The three test methods used most often to evaluate in vitro drug release profiles of nanoparticles are direct addition, dialysis bag, and lowpressure ultrafiltration; however, the basic principles and specifications of these three methods are different and each method has specific limitations and/or drawbacks (19-37). Scientists have also highlighted technical difficulties with using these methods $(38,39)$. Hence, the reported drug release data of nanoparticle-based products are not conclusively comparable and therefore cannot be universally acceptable due to variations in testing procedures. No attempt has been made to reconcile these issues and establish a standard in vitro dissolution test that can be unequivocally employed for quality control of nanoparticle-based drug formulations by all investigators.

The objective of the present study was to evaluate and compare the relevant operational parameters of the most 
commonly used in vitro drug release methods, i.e., direct addition, dialysis bag, and low-pressure ultrafiltration, to establish their relative appropriateness for the possibility of uniform adoption of one method for quality control of nanoparticle-based products. The studies were performed using tamoxifen-loaded poly(lactic-co-glycolic acid) (PLGA) nanoparticles as a model.

\section{MATERIALS AND METHODS}

\section{Materials}

Tamoxifen citrate was received from Cadila Healthcare Ltd (Ahmedabad, India) as a gift sample. PLGA 50:50 (Resomer RG 504H, intrinsic viscosity 0.45-0.60) was kindly donated by Evonik India. Polyvinyl alcohol (87-90\% hydrolyzed, MW 30,000-70,000) was purchased from Sigma Aldrich. Sodium lauryl sulfate, disodium hydrogen phosphate, sodium dihydrogen phosphate, sodium hydroxide, methanol, and dichloromethane (analytical grade) were purchased from S. d. Fine Chem. (India).

\section{Preparation of Tamoxifen Nanoparticles}

Tamoxifen nanoparticles were prepared using an emulsification solvent evaporation method, as shown in Figure 1 (40). Tamoxifen (20 mg) and PLGA (180 mg) were dissolved in $10 \mathrm{~mL}$ of a dichloromethane and methanol (4:1) solvent blend. The drug-polymer solution (oil phase) was added dropwise into previously cooled $200 \mathrm{~mL}$ of $0.2 \%$ polyvinyl alcohol (PVA) aqueous solution, then the mixture was probe sonicated (Vibra-cell-Sonics) for 5 min at $50 \%$ amplitude in an ice bath. The emulsion was stirred on a magnetic stirrer for $12 \mathrm{~h}$ to evaporate the solvent and generate solid PLGA nanoparticles of tamoxifen. The resulting dispersion was centrifuged (C-24, Remi, India) for $30 \mathrm{~min}$ at $36,000 \mathrm{rcf}$ to separate the tamoxifen-loaded nanoparticles. The obtained nanoparticles were washed three times by milli-Q water to remove any traces of PVA. Finally, the nanoparticles were lyophilized using $5 \%$ trehalose as a cryoprotectant using benchtop lyophilizer (VirTis, SP Scientific).

\section{Determination of Drug Content and Entrapment Efficiency}

A weighed quantity of tamoxifen-loaded nanoparticles was transferred in a volumetric flask and dissolved in dichloromethane and methanol solvent blend (1:4) and analyzed on a UV-visible spectrophotometer (Shimadzu) at $275 \mathrm{~nm}$ and the drug content was calculated. The encapsulation efficiency of nanoparticles was determined by the formula reported by Zhang and Feng (25).

\section{Determination of Particle Size, Zeta Potential, and Polydispersity Index}

The particle size ( $Z$ average), zeta potential, and polydispersity index were determined using dynamic light scattering (DLS) and microelectrophoresis methods, respectively, in a nano particle size analyzer (Nanotrac Wave, Microtrac, Inc.). The freeze-dried nanoparticles were dispersed in milli-Q water and bath sonicated for a few seconds, then particle size, zeta potential, and polydispersity index were analyzed in triplicate. The surface morphology of nanoparticles was analyzed by scanning electron microscopy (Supra 55 Zeiss). The test samples were prepared on aluminium stubs with adhesive tape, and a thin layer of gold coating was applied using a sputtering unit at acceleration at $5 \mathrm{kV}$.

\section{In Vitro Drug Release Study}

In vitro drug release of tamoxifen-loaded nanoparticles was determined separately by three methods, i.e., direct

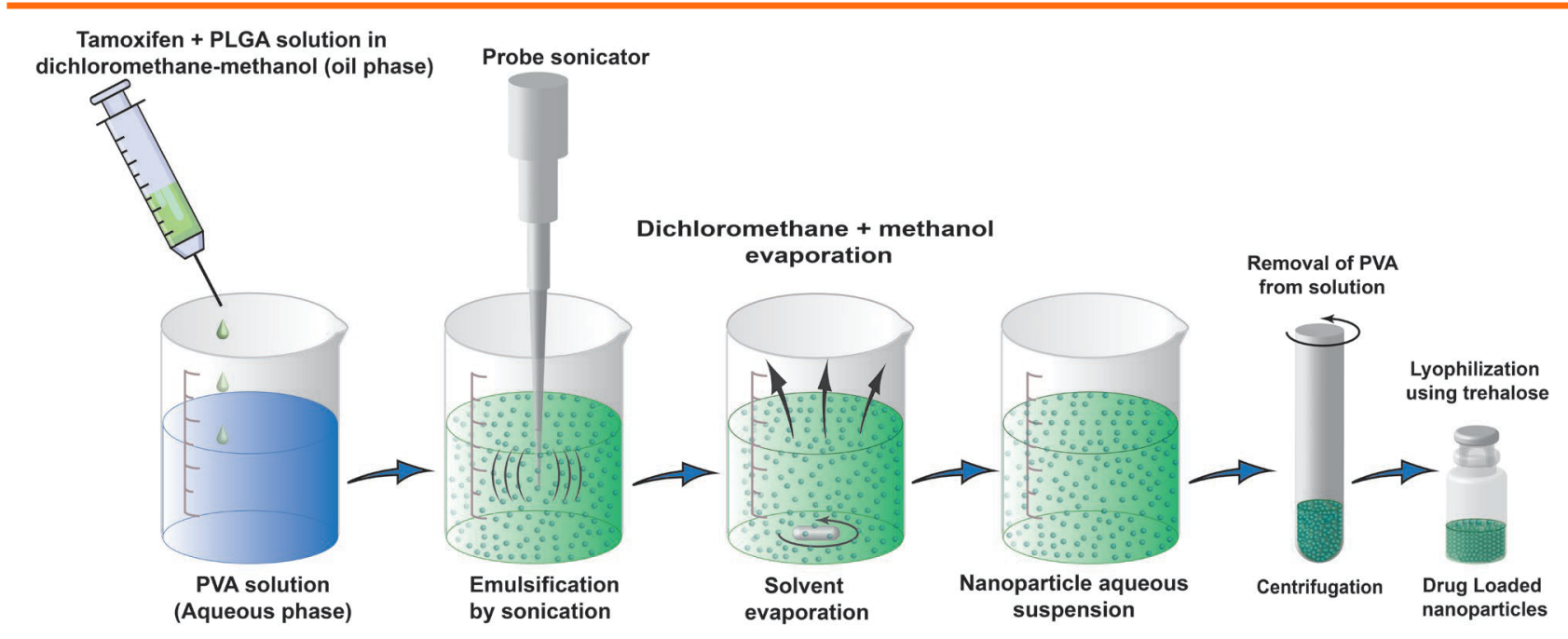

Figure 1. Preparation of tamoxifen-loaded PLGA (50:50) nanoparticles by emulsification solvent evaporation method. 
addition, dialysis bag, and low-pressure ultrafiltration (19, $29,33)$. The studies were performed under sink conditions using a phosphate buffer $(\mathrm{pH} 7.4)$ with $0.5 \%$ SLS solution as the drug release medium. The solubility of tamoxifen citrate in phosphate buffer $(\mathrm{pH} 7.4)$ with $0.5 \% \mathrm{SLS}$ solution was $1.2 \mathrm{mg} / \mathrm{mL}$.

\section{Direct addition method}

A weighed quantity $(50 \mathrm{mg}$ ) of drug-loaded nanoparticles was added in a beaker containing $200 \mathrm{~mL}$ of drug release media and stirred at $100 \mathrm{rpm}$ on magnetic stirrer, as shown in Figure 2. A 5-mL aliquot of dissolution fluid was withdrawn at different time intervals and replenished with an equal volume of fresh media after each withdrawal (19). The withdrawn samples were centrifuged for $15 \mathrm{~min}$ at 11,000 rcf (Eppendorf cooling centrifuge), filtered through a $0.22-\mu \mathrm{m}$ polyvinylidene fluoride (PVDF) membrane filter, and analyzed with a UVvisible spectrophotometer at $275 \mathrm{~nm}$.

\section{Dialysis bag method}

The dialysis bag was a regenerated cellulose membrane (molecular weight cut-off [MWCO] 12-14 kDa; LA395$1 \mathrm{MT}$, Himedia). It was treated according to the prescribed standard procedure and kept overnight in dissolution media to ensure thorough wetting of the membrane (41). A weighed amount $(50 \mathrm{mg}$ ) of drug-loaded nanoparticles was dispersed in $3 \mathrm{~mL}$ dissolution media and transferred into the dialysis bag (donor compartment). The ends of the dialysis bag were clamped and placed in a beaker containing $200 \mathrm{~mL}$ of dissolution media (receptor compartment) and stirred with a magnetic bead at $100 \mathrm{rpm}$ at room temperature, as shown in Figure 2. A control study was simultaneously performed in which tamoxifen solution in dissolution media was filled into a dialysis bag in place of nanoparticles dispersion to assess free drug diffusion through dialysis bag membrane. A $5-\mathrm{mL}$ aliquot of dissolution fluid was withdrawn from the receptor compartment at different time points and replenished with an equal volume of fresh media after each withdrawal. The withdrawn samples were analyzed with a UV-visible spectrophotometer at $275 \mathrm{~nm}$.

\section{Low-pressure ultrafiltration method}

The study of drug release by low-pressure ultrafiltration was performed in a stirred cell ultrafiltration unit, as shown in Figure 2. The base plate of the stirred cell was fitted with a polyethersulfone ultrafiltration membrane (MWCO 300,000; Biomax, Millipore Corp.) for separating the released drug from nanoparticles. A weighed amount (50 mg) of nanoparticles was placed in the stirred cell containing $200 \mathrm{~mL}$ of dissolution media and the dispersion was stirred at $100 \mathrm{rpm}$. A 5-mL aliquot of drug sample was collected at predetermined time intervals from the outlet of tubing attached to the bottom of the plate by introducing a low-pressure nitrogen gas into a glass chamber, then an equal volume of fresh media was replenished through a media filling inlet port after each sample collection. The collected samples were analyzed with a UV-visible spectrophotometer at $275 \mathrm{~nm}$.

\section{Operational Characteristics of In Vitro Release Test Methods}

Every in vitro release test method is primarily intended to quantify the drug released from drug delivery system in the surrounding fluid medium with respect to time after its administration. Among the different methods employed, if the basic operational characteristics of a

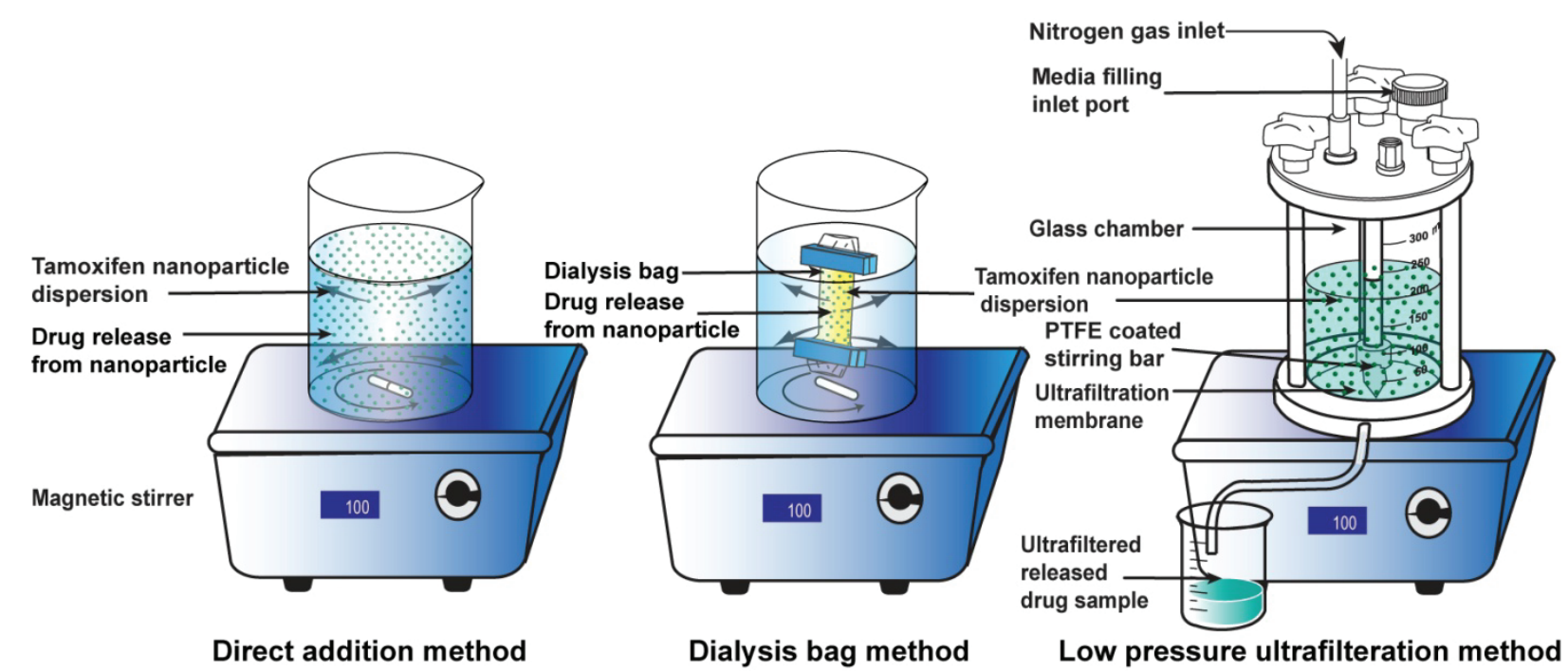

Figure 2. In-vitro drug release test methods employed for evaluation of tamoxifen-loaded PLGA (50:50) nanoparticles. 
method vary, then there can be a significant variation in the obtained drug release data for the same drug product evaluated by different test methods.

The most important operational characteristics that may lead to significant variation in drug release test data include: volume of drug release medium present and sampled; ease of sampling of released drug fraction from the total fluid present; presence of additional barrier between available and sampled fluid; ease and extent of maintaining sink condition; additional step involved for isolation of released drug from the sampled nanoparticle fluid dispersion; ease of "burst release" estimation; and efficiency of isolation of dispersed nanoparticles from the sampled test fluid. Burst release is referred to as the sudden large amount of bolus drug released after adding nanoparticles in the dissolution medium, before obtaining a stable release profile (42).

The operational characteristics are compared for each method in Table 1.

Table 1. Comparison of Relevant Operational Parameters of In Vitro Drug Release Methods for Nanoparticles

\begin{tabular}{|c|c|c|c|}
\hline Parameter & Direct Addition Method & Dialysis Bag Method & Low-Pressure Ultrafiltration Method \\
\hline Volume of drug release media used & 200 mL (adequate) & 3-5 mL (limited) & 100-200 mL (adequate) \\
\hline $\begin{array}{l}\text { Additional barrier present for } \\
\text { released drug }\end{array}$ & Not present & Present (dialysis membrane) & $\begin{array}{l}\text { Present (ultrafiltration membrane) but } \\
\text { does not act as barrier for released drug }\end{array}$ \\
\hline $\begin{array}{l}\text { Direct sampling of released drug } \\
\text { from nanoparticle dispersion }\end{array}$ & Not possible & Not possible & Possible \\
\hline Ease of released drug sampling & Not easy (requires separation) & $\begin{array}{l}\text { Not easy (released drug has to cross } \\
\text { dialysis membrane barrier) }\end{array}$ & Easy and instant \\
\hline $\begin{array}{l}\text { Additional step involved in the } \\
\text { sampled fluid processing }\end{array}$ & High-speed centrifugation & NA & Low nitrogen gas pressure generation \\
\hline $\begin{array}{c}\text { Time elapsed between } \\
\text { nanoparticle dispersion fluid } \\
\text { sampling and obtaining released } \\
\text { drug solution sample }\end{array}$ & $15-20 \mathrm{~min}$ & NA & $5-10 s$ \\
\hline Status of sink condition & Maintained & Not maintained & Maintained \\
\hline Critical operational variables & $\begin{array}{ll}\text { - } & \text { Centrifugation speed } \\
\text { - } & \text { Centrifugation time } \\
& \text { Time of separation of } \\
\text { released drug sample } \\
\text { from nanoparticle } \\
\text { dispersion }\end{array}$ & $\begin{array}{l}\text { - } \quad \text { Molecular weight cutoff of } \\
\text { dialysis bag membrane } \\
\text { Dialysis bag area } \\
\text { - } \quad \text { Dialysis rate }\end{array}$ & $\begin{array}{l}\text { Gas pressure applied in the stirred } \\
\text { cell chamber }\end{array}$ \\
\hline $\begin{array}{l}\text { Impact of critical operational } \\
\text { variables on drug release data of } \\
\text { nanoparticles }\end{array}$ & $\begin{array}{l}\text { - High speed centrifugation } \\
\text { significantly affects drug } \\
\text { release data; high (> } \\
\text { 10,000 rcf) centrifugal } \\
\text { pressure can increase } \\
\text { drug release rate and can } \\
\text { add significant amount of } \\
\text { drug in the sample due } \\
\text { to drug released during } \\
\text { centrifugation from } \\
\text { nanoparticles } \\
\text { Centrifugation time } \\
\text { significantly affects } \\
\text { drug release data due } \\
\text { to additional drug } \\
\text { released in centrifugation } \\
\text { duration. The effect } \\
\text { is proportional to } \\
\text { centrifugation time. }\end{array}$ & $\begin{array}{l}\text { Dialysis membrane } \\
\text { permeability significantly } \\
\text { affects drug release data as } \\
\text { the dialysis of released drug } \\
\text { from donor compartment to } \\
\text { receptor compartment is time } \\
\text { dependent }\end{array}$ & $\begin{array}{l}\text { - Gas pressure does not significantly } \\
\text { affect drug release data }\end{array}$ \\
\hline $\begin{array}{c}\text { Estimation of accurate real } \\
\text { time burst release of drug from } \\
\text { nanoparticles }\end{array}$ & Not feasible & Not feasible & Feasible \\
\hline
\end{tabular}

NA: not applicable 


\section{Direct addition method}

In this method, though the volume of dissolution medium is adequately large $(\sim 200 \mathrm{~mL})$ and the nanoparticles remain dispersed throughout with no additional barrier, the sampling of fluid containing only released drug is not direct because the nanoparticle dispersion is withdrawn. Therefore, an additional step is needed to separate the released drug from the sampled dispersion fluid, i.e., high-speed centrifugation (11,000 rcf) for about 15 min. However, high-speed centrifugation for 15 min may hinder the ability to accurately estimate burst release and drug release at sampling points in real-time. Thus, the data from this method represent actual plus an additional amount of drug released during sample processing ( $15 \mathrm{~min})$. However, the sink condition can be readily maintained in this method due to large volume of dissolution medium used.

\section{Dialysis bag method}

In this method, direct sampling of the released drug solution without the dispersed nanoparticles is possible due to presence of the dialysis membrane, which acts as a barrier between the dispersion fluid and separated drug solution. The volume of the dialysis bag and dissolution medium is limited, varying from 3 to $5 \mathrm{~mL}$, so less samples are taken to maintain sink condition. However, it is not possible to maintain the sink condition because the released drug cannot be directly sampled from the donor compartment and its passage into the receptor compartment for removal is not a rapid and one-way process. Further, volume of the dissolution medium in the receptor compartment is normally $100-200 \mathrm{~mL}$, and many times a small quantity of drug released after dialysis in the receptor compartment gets diluted with dissolution medium to the extent that the drug concentration falls below the limit of quantification. Owing to all of these issues, burst release estimation is not possible with this method.

\section{Low-pressure ultrafiltration method}

In this method, an adequately large volume (100-200 $\mathrm{mL}$ ) of dissolution medium can be taken in the stirred cell chamber to maintain sink condition. The burst release of drug from nanoparticles can be precisely estimated by introducing low-pressure nitrogen gas in the ultrafiltration chamber, allowing for instant separation of released drug from dispersion fluid and sampling. The membrane at the base of the chamber filters the released drug from the nanoparticle dispersion fluid. Because the gas pressure is low, it does not affect normal drug release from the nanoparticles, contrary to the effect of high centrifugal force employed in the direct addition method. The rate of ultrafiltration under generated gas pressure is so fast that the filtrate collected at any given time point gives the real time drug release data; therefore, an accurate burst release drug estimation is possible. Contrary to the membrane used in the dialysis bag method, the ultrafiltration membrane does not act as a barrier to the released drug because of the gas pressure employed. Thus, instant separation of released drug from the nanoparticles can be done using the low-pressure ultrafiltration method.

\section{Drug Release Kinetics}

To interpret drug release data, the kinetics of drug release are assessed by various models. The zero order release kinetics model shows that the rate of drug release does not depend on any factor. Whereas the first order release kinetics model shows that the rate of drug release from the system is dependent on any one factor such as concentration. The Higuchi model on the other hand shows drug release from polymeric matrix based on Fickian diffusion with respect to square root of time. The Hixson-Crowell drug release model applies to a system wherein the diameter of particle decreases with time and hence the release of drug is reduced as time passes. The Korsmeyer-Peppas model describes the Fickian, nonFickian, and anomalous release behavior of controlled release polymeric systems of thin film, cylinders, spheres, and polydisperse samples through a simple exponential relation: $M_{t} / M_{\infty}=k t^{n}$. The drug release exponent $(n)$ in this model is an important indicator of the drug release mechanism $(43,44)$.

\section{RESULTS AND DISCUSSION \\ Encapsulation Efficiency and Particle Size Analysis of Tamoxifen-Loaded Nanoparticles}

Encapsulation efficiency of drug-loaded nanoparticles was found to be $71.6 \%$. The particle size, zeta potential, and polydispersity index of the nanoparticles were 267.2 $\mathrm{nm},+21 \mathrm{mv}$, and 0.753 , respectively.

\section{Drug Release Data Interpretation and Assessment of Drug Release Kinetics}

Results of the dissolution tests are presented in Table 2 and Figure 3. Drug release kinetic modeling data are presented in Table 3.

Amongst all five drug release kinetics models, the highest coefficient of determination $\left(R^{2}\right)$ in all three methods was obtained in Korsmeyer-Peppas model. Therefore, drug release from tamoxifen nanoparticles followed the Korsmeyer-Peppas model in all three dissolution test methods (45-47).

The drug release $(n)$ value in the Korsmeyer-Peppas model indicates the drug release mechanism. An $n$ value $<0.43$ 


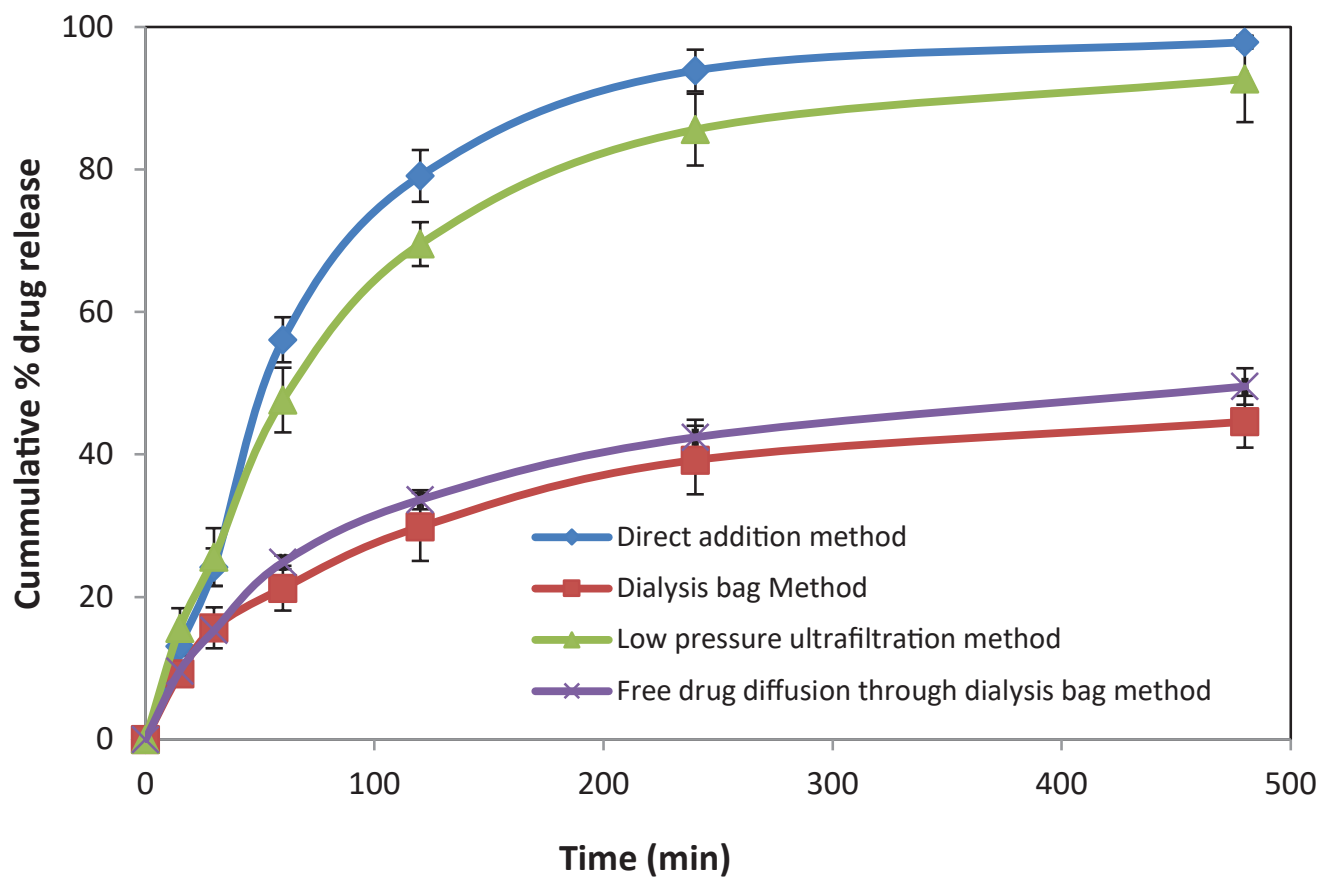

Figure 3. Comparison of methods for in vitro drug release of tamoxifen nanoparticles.

Table 2. In Vitro Drug Release of Tamoxifen Nanoparticles by Different Methods and Free Drug Diffusion Through Dialysis Bag

\begin{tabular}{|c|c|c|c|c|}
\hline \multirow{2}{*}{ Time (min) } & \multicolumn{3}{|c|}{ Cumulative Drug Released (Mean \% \pm SD) } & $\begin{array}{c}\text { Free Drug Diffusion } \\
\text { Through Dialysis Bag }\end{array}$ \\
\cline { 2 - 5 } & Direct Addition Method & Dialysis Bag Method & $\begin{array}{c}\text { Low-Pressure Ultrafiltration } \\
\text { Method }\end{array}$ & $0.00 \pm 0.00$ \\
\hline 0 & $0.00 \pm 0.00$ & $0.00 \pm 0.00$ & $15.61 \pm 2.81$ & $9.61 \pm 1.12$ \\
\hline 15 & $13.06 \pm 1.27$ & $9.20 \pm 1.78$ & $25.59 \pm 4.07$ & $15.30 \pm 1.26$ \\
\hline 30 & $24.19 \pm 2.63$ & $15.67 \pm 2.87$ & $47.64 \pm 4.54$ & $24.85 \pm 0.96$ \\
\hline 60 & $56.10 \pm 3.16$ & $21.23 \pm 3.14$ & $69.53 \pm 3.08$ & $33.64 \pm 1.34$ \\
\hline 120 & $79.10 \pm 3.64$ & $29.83 \pm 4.78$ & $85.59 \pm 5.04$ & $42.41 \pm 2.46$ \\
\hline 240 & $93.89 \pm 2.93$ & $39.22 \pm 4.81$ & $92.70 \pm 6.05$ & $49.54 \pm 2.56$ \\
\hline 480 & $97.86 \pm 0.88$ & $44.60 \pm 3.64$ & & 4 \\
\hline
\end{tabular}

Table 3. Drug Release Rate Constant (k) of Tamoxifen-Loaded Nanoparticles for Three Different Methods Using Different Drug Release Kinetic Models

\begin{tabular}{|l|c|c|c|}
\hline \multirow{2}{*}{ Drug release kinetic model } & \multicolumn{2}{|c|}{$k$ (\% release amount/min) } & $\begin{array}{c}\text { Low-Pressure Ultrafiltration } \\
\text { Method }\end{array}$ \\
\cline { 2 - 4 } & Direct Addition Method & Dialysis Bag Method & $1.771 \times 10^{-1}$ \\
\hline Zero order & $1.9 \times 10^{-1}$ & $8.2 \times 10^{-2}$ & $2.6 \times 10^{-3}$ \\
\hline First order & $3.6 \times 10^{-3}$ & $5.0 \times 10^{-4}$ & $4.6712^{*}$ \\
\hline Higuchi & $5.0369^{*}$ & $2.113^{*}$ & $5.8 \times 10^{-3}$ \\
\hline Hixon-Crowell & $7.1 \times 10^{-3}$ & $1.6 \times 10^{-3}$ & $7.55 \times 10^{-2}$ \\
\hline $\begin{array}{l}\text { Korsmeyer-Peppas } \\
\text { Release exponent }(\mathrm{n})\end{array}$ & $7.8 \times 10^{-2}$ & $6.2 \times 10^{-2}$ & 0.839 \\
Drug transport mechanism & 1.131 & Non-Fickian transport & Non-Fickian transport \\
\hline
\end{tabular}

*Percent drug release amount $/ \mathrm{min}^{1 / 2}$ 
is Fickian diffusion, $0.43-1.00$ is non - Fickian transport, $n$ $=1.0$ indicates case II transport, and $\mathrm{n}>1.0$ shows super case II transport $(48,49)$. In the current study, $n=1.131$ in the direct addition method (super case II transport); 0.558 in the dialysis method (non-Fickian transport); and 0.839 in low-pressure ultrafiltration method (non-Fickian). In light of these differences, it was necessary to apply some other parameters to conclusively identify which of the three dissolution tests provided the most accurate drug release data.

The drug release rate constant $(k)$ is measured as the percentage of released drug per minute. The $k$ value for the direct addition method was $7.8 \times 10-2$, followed by the low-pressure ultrafiltration method $7.5 \times 10-2$, and the dialysis bag method, $6.2 \times 10-2$. The highest release rate demonstrated by direct addition method may be attributed to the additional time involved in processing of sampled dispersion fluid, i.e., centrifugal separation of clear drug solution for estimation. The lowest drug release rate from nanoparticles depicted by dialysis bag method can be ascribed to the presence of the membrane barrier and limited surface area of dialysis bag available for drug diffusion. Because the low-pressure ultrafiltration method was devoid of the operational constraints associated with other methods, it can be inferred that this method provided the most accurate real-time in vitro drug release data for tamoxifen nanoparticles among the three methods.

\section{CONCLUSION}

The direct addition and dialysis bag methods for invitro drug release testing are associated with different kinds of operational constraints and thereby real-time drug release data of nanoparticles are not obtained. The operational constraints with these methods hinder accurate burst release estimation of drug products. However, drug release data obtained with the lowpressure ultrafiltration method enable the investigator to accurately determine a real-time drug release profile including burst release. No major operational constraints are associated with this method, contrary to the direct addition and dialysis bag methods. The low-pressure ultrafiltration method for in-vitro dissolution testing possesses all attributes desired in a standard in-vitro release method. This method can be a useful tool for drug release profile characterization in development of a generic nanoparticle-based drug delivery system. Additionally, the principles applied in this technique can be further adopted to establish a pharmacopeial standard for in-vitro drug release of nanoparticles using an appropriately modified USP dissolution apparatus to work with a low-pressure ultrafiltration method.

\section{ACKNOWLEDGEMENTS}

The Authors thank the Indian Institute of Technology (Indore) for assistance with scanning electron microscopic analysis, Zydus Research Center (Ahmedabad) for providing tamoxifen, and Evonik India Pvt. Ltd. (Mumbai) for providing PLGA 50:50.

\section{FUNDING}

This work was supported by grants for research facilities from the All India Council of Technical Education (New Delhi) and Madhya Pradesh Council of Science and Technology (Bhopal).

\section{CONFLICT OF INTEREST}

The authors disclosed no conflicts of interest related to this article.

\section{REFERENCES}

1. Baetke, S. C.; Lammers, T.; Kiessling, F. Applications of nanoparticles for diagnosis and therapy of cancer. Br. J. Radiol. 2015, 88, 20150207. DOI: 10.1259/bjr.20150207.

2. Radomska, A.; Leszczyszyn, J.; Radomski, M. W. The nanopharmacology and nanotoxicology of nanomaterials: new opportunities and challenges. Adv. Clin. Exp. Med. 2016, 25, 151-62. DOI: 10.17219/acem/60879.

3. Verreck, G.; Chun, I.; Rosenblatt, J.; Peeters, J.; Dijck, A. V.; Mensch, J.; Noppe, M.; Brewster, M. E. Incorporation of drugs in an amorphous state into electrospun nanofibers composed of a water-insoluble, nonbiodegradable polymer. J. Control. Release 2003, 92, 349-360. DOI: 10.1016/S0168-3659(03)00342-0.

4. Heiati, H.; Tawashi, R.; Shivers, R. R.; Phillips, N. C. Solid lipid nanoparticles as drug carriers. I. Incorporation and retention of the lipophilic prodrug 3'-azido-3'-deoxythymidine palmitate. Int. J. Pharm. 1997, 146, 123-131. DOI: 10.1016/S03785173(96)04782-5.

5. Cetin, M.; Atila, A.; Kadioglu, Y. Formulation and in vitro characterization of Eudragit ${ }^{\circledR}$ L100 and Eudragit ${ }^{\circledR}$ L100-PLGA nanoparticles containing diclofenac sodium. AAPS PharmSciTech 2010, 11, 1250-1256. DOI: 10.1208/s12249-010-9489-6.

6. Bi, Y. E.; Zhou, Y.; Wang, M.; Li, L.; Lee, R. J.; Xie, J.; Teng, L. Targeted delivery of cordycepin to liver cancer cells using transferrin-conjugated liposomes. Anticancer Res. 2017, 37, 5207-5214. DOI: 10.21873/anticanres.11944.

7. Jiang, G.; Li, R.; Tang, J.; Ma, Y.; Hou, X.; Yang, C.; Guo, W.; Xin, Y.; Liu, Y. Formulation of temozolomide-loaded nanoparticles and their targeting potential to melanoma cells. Oncol. Rep. 2017, 37, 995-1001. DOI: 10.3892/or.2016.5342.

8. Lammers, T.; Kiessling, F.; Hennink, W. E.; Storm, G. Drug targeting to tumors: principles, pitfalls and (pre-) clinical progress. J. Control. Release 2012, 161, 175-187. DOI: 10.1016/j. jconrel.2011.09.063.

9. Walkey, C. D.; Chan, W. C. Understanding and controlling the interaction of nanomaterials with proteins in a physiological 
environment. Chem. Soc. Rev. 2012, 41, 2780-2799. DOI: 10.1039/c1cs15233E.

10. Wong, H. L.; Wu, X. Y.; Bendayan, R. Nanotechnological advances for the delivery of CNS therapeutics. Adv. Drug Deliv. Rev. 2012, 64, 686-700. DOI: 10.1016/j.addr.2011.10.007.

11. Flores, A. M.; Ye, J.; Jarr, K. U.; Hosseini-Nassab, N.; Smith, B. R.; Leeper, N. J. Nanoparticle therapy for vascular diseases. Arterioscler. Thromb. Vasc. Bio.I 2019, 39, 635-646. DOI: 10.1161/ATVBAHA.118.311569.

12. Pujol-Autonell, I.; Mansilla, M. J.; Rodriguez-Fernandez, S.; Cano-Sarabia, M.; Navarro-Barriuso, J.; Ampudia, R. M.; Rius, A.; Garcia-Jimeno, S.; Perna-Barrull, D.; Martinez-Caceres, E.; Maspoch, D.; Vives-Pi, M. Liposome-based immunotherapy against autoimmune diseases: therapeutic effect on multiple sclerosis. Nanomedicine (Lond) 2017, 12, 1231-1242. DOI: 10.2217/nnm-2016-0410.

13. Bahman, F.; Greish, K.; Taurin, S. Nanotechnology in insulin delivery for management of diabetes. Pharm. Nanotechnol. 2019, 7, 113-128. DOI: 10.2174/221173850766619032111072 1.

14. Sanna, V.; Pala, N.; Sechi, M. Targeted therapy using nanotechnology: focus on cancer. Int. J. Nanomedicine 2014, 9, 467-483. DOI: 10.2147/IJN.S36654.

15. Kreuter, J. Nanoparticle-based dmg delivery systems. J. Control. Release 1991, 16, 169-176. DOI: 10.1016/0168-3659(91)90040K.

16. Etheridge, M. L.; Campbell, S. A.; Erdman, A. G.; Haynes, C. L.; Wolf, S. M.; McCullough, J. The big picture on nanomedicine: the state of investigational and approved nanomedicine products. Nanomedicine 2013, 9, 1-14. DOI: 10.1016/j.nano.2012.05.013.

17. Gupta, R. B. Fundamentals of drug nanoparticles. In Drugs and the pharmaceutical sciences: Nanoparticle Technology for Drug Delivery, Taylor \& Francis Group: New York, 2006; Vol. 159, pp 6-9.

18. Couvreur, P.; Vauthier, C. Nanotechnology: intelligent design to treat complex disease. Pharm. Res. 2006, 23, 1417-1450. DOI: 10.1007/s11095-006-0284-8.

19. Danhier, F.; Lecouturier, N.; Vroman, B.; Jérôme, C.; MarchandBrynaert, J.; Feron, O.; Preat, V. Paclitaxel-loaded PEGylated PLGAbased nanoparticles: in vitro and in vivo evaluation. J. Control. Release 2009, 133, 11-17. DOI: 10.1016/j.jconrel.2008.09.086.

20. Li, Y.; Pei, Y.; Zhang, X.; Gu, Z.; Zhou, Z.; Yuan, W.; Zhou, J.; Zhu, J.; Gao, X. PEGylated PLGA nanoparticles as protein carriers: synthesis, preparation and biodistribution in rats. J. Control. Release 2001, 71, 203-211. DOI: 10.1016/S01683659(01)00218-8.

21. Dong, Y.; Feng, S.S. Poly(d,I-lactide-co-glycolide)/montmorillonite nanoparticles for oral delivery of anticancer drugs. Biomaterials 2005, 26, 6068-6076. DOI: 10.1016/j.biomaterials.2005.03.021.

22. Lee, S. H.; Zhang, Z.; Feng, S. S. Nanoparticles of poly(lactide)tocopheryl polyethylene glycol succinate (PLA-TPGS) copolymers for protein drug delivery. Biomaterials 2007, 28, 2041-2050.
DOI: 10.1016/j.biomaterials.2007.01.003.

23. Liu, Y.; Pan, J.; Feng, S. S. Nanoparticles of lipid monolayer shell and biodegradable polymer core for controlled release of paclitaxel: effects of surfactants on particles size, characteristics and in vitro performance. Int. J. Pharm. 2010, 395, 243-250. DOI: 10.1016/j.ijpharm.2010.05.008.

24. Westedt, U.; Kalinowski, M.; Wittmar, M.; Merdan, T.; Unger, F.; Fuchs, J.; Schäller, S.; Bakowsky, U.; Kissel, T. Poly(vinyl alcohol)graft-poly(lactide-co-glycolide) nanoparticles for local delivery of paclitaxel for restenosis treatment. J. Control. Release 2007, 119, 41-51. DOI: 10.1016/j.jconrel.2007.01.009.

25. Zhang, Z.; Feng, S. S. The drug encapsulation efficiency, in vitro drug release, cellular uptake and cytotoxicity of paclitaxelloaded poly(lactide)-tocopheryl polyethylene glycol succinate nanoparticles. Biomaterials 2006, 27, 4025-4033. DOI: 10.1016/j.biomaterials.2006.03.006.

26. Chidambaram, N.; Burgess, D. J. A novel in vitro release method for submicron sized dispersed systems. AAPS PharmSci 1999, 1, E11. DOI: 10.1208/ps010311.

27. Gao, C.; Pan, J.; Lu, W.; Zhang, M.; Zhou, L.; Tian, J. In-vitro evaluation of paclitaxel-loaded MPEG-PLGA nanoparticles on laryngeal cancer cells. Anticancer Drugs 2009, 20, 807-814. DOI: 10.1097/CAD.0b013e328330c811.

28. Hashem, F. M.; Nasr, M.; Khairy, A., In vitro cytotoxicity and bioavailability of solid lipid nanoparticles containing tamoxifen citrate. Pharm. Dev. Technol. 2014, 19, 824-832. DOI: 10.3109/10837450.2013.836218.

29. Kheradmandnia, S.; Vasheghani-Farahani, E.; Nosrati, M.; Atyabi, F. Preparation and characterization of ketoprofenloaded solid lipid nanoparticles made from beeswax and carnauba wax. Nanomedicine 2010, 6, 753-759. DOI: 10.1016/j. nano.2010.06.003.

30. Ling, G.; Zhang, P.; Zhang, W.; Sun, J.; Meng, X.; Qin, Y.; Deng, Y.; He, Z. Development of novel self-assembled DS-PLGA hybrid nanoparticles for improving oral bioavailability of vincristine sulfate by P-gp inhibition. J. Control. Release 2010, 148, 241248. DOI: 10.1016/j.jconrel.2010.08.010.

31. Mehta, A. K.; Yadav, K. S.; Sawant, K. K. Nimodipine loaded PLGA nanoparticles: formulation optimization using factorial design, characterization and in vitro evaluation. Curr. Drug Deliv. 2007, 4, 185-193. DOI: 10.2174/156720107781023929.

32. Saarinen-Savolainen, P.; Järvinen, T.; Taipale, H.; Urtti, A. Method for evaluating drug release from liposomes in sink conditions. Int. J. Pharm. 1997, 159, 27-33. DOI: 10.1016/S03785173(97)00264-0.

33. Magenheim, B.; Levy, M. Y.; Benita, S. A new in vitro technique for the evaluation of drug release profile from colloidal carriers ultrafiltration technique at low pressure. Int. J. Pharm. 1993, 94, 115-123. DOI: 10.1016/0378-5173(93)90015-8.

34. Rosenblatt, K. M.; Douroumis, D.; Bunjes, H. Drug release from differently structured monoolein/poloxamer nanodispersions studied with differential pulse polarography and ultrafiltration at

Dissolution 
low pressure. J. Pharm. Sci. 2007, 96, 1564-1575. DOI: 10.1002/ jps.20808.

35. Yue, P. F.; Lu, X. Y.; Zhang, Z. Z.; Yuan, H. L.; Zhu, W. F.; Zheng, Q.; Yang, M. The study on the entrapment efficiency and in vitro release of puerarin submicron emulsion. AAPS PharmSciTech 2009, 10, 376-383. DOI: 10.1208/s12249-009-9216-3.

36. Cui, J.; Li, C.; Deng, Y.; Wang, Y.; Wang, W. Freeze-drying of liposomes using tertiary butyl alcohol/water cosolvent systems. Int. J. Pharm. 2006, 312, 131-136. DOI: 10.1016/j. ijpharm.2006.01.004.

37. Boyd, B. J. Characterisation of drug release from cubosomes using the pressure ultrafiltration method. Int. J. Pharm. 2003, 260, 239-247. DOI: 10.1016/S0378-5173(03)00262-X.

38. Washington, C. Drug release from microdisperse systems: a critical review. Int. J. Pharm. 1990, 58, 1-12. DOI: 10.1016/03785173(90)90280-H.

39. Magenheim, B.; Benita, S. Nanoparticle characterization:a comprehensive physicochemical approach. STP Pharm. Sci. 1991, 1, 221-241.

40. Paswan, S. K.; Saini, T. R. Purification of drug loaded PLGA nanoparticles prepared by emulsification solvent evaporation using stirred cell ultrafiltration technique. Pharm. Res. 2017, 34, 2779-2786. DOI: 10.1007/s11095-017-2257-5.

41. LA395 Dialysis Membrane-110. Himedia. http://himedialabs. com/TD/LA395.pdf. Accessed April 26, 2019.

42. Huang, X.; Brazel, C. S. On the importance and mechanisms of burst release in matrix-controlled drug delivery systems. J. Control. Release 2001, 73, 121-136. DOI: 10.1016/S01683659(01)00248-6.
43. Costa, P.; Sousa Lobo, J. M. Modeling and comparison of dissolution profiles. Eur. J. Pharm. Sci. 2001, 13, 123-133. DOI: 10.1016/s0928-0987(01)00095-1.

44. 44. Dash, S.; Murthy, P. N.; Nath, L.; Chowdhury, P. Kinetic modeling on drug release from controlled drug delivery systems. Acta Pol. Pharm. 2010, 67, 217-223.

45. Brito, A. E. M.; Pessoa, A., Jr.; Converti, A.; Rangel-Yagui, C. O.; Silva, J. A. D.; Apolinario, A. C. Poly (lactic-co-glycolic acid) nanospheres allow for high I-asparaginase encapsulation yield and activity. Mater. Sci. Eng. C 2019, 98, 524-534. DOI: 10.1016/j. msec.2019.01.003.

46. Essaghraoui, A.; Belfkira, A.; Hamdaoui, B.; Nunes, C.; Lima, S. A. C.; Reis, S. Improved dermal delivery of cyclosporine a loaded in solid lipid nanoparticles. Nanomaterials (Basel) 2019, 9, 1204. DOI: 10.3390/nano9091204.

47. Sarkar, P.; Bhattacharya, S.; Pal, T. K. Application of statistical design to evaluate critical process parameters and optimize formulation technique of polymeric nanoparticles. R. Soc. Open Sci. 2019, 6, 190896. DOI: 10.1098/rsos.190896.

48. Korsmeyer, R. W.; Gurny, R.; Doelker, E.; Buri, P.; Peppas, N. A. Mechanisms of solute release from porous hydrophilic polymers. Int. J. Pharm. 1983, 15, 25-35. DOI: 10.1016/03785173(83)90064-9.

49. Ritger, P. L.; Peppas, N. A. A simple equation for description of solute release I. Fickian and non-Fickian release from nonswellable devices in the form of slabs, spheres, cylinders or discs. J. Control. Release 1987, 5, 23-36. DOI: 10.1016/01683659(87)90034-4. 